\title{
The impact evaluation of soil liquefaction on low-rise building in the Meinong earthquake
}

\author{
Chih-Chieh Lu*, Jin-Hung Hwang ${ }^{2}$ and Shang-Yi Hsu
}

\begin{abstract}
This paper presents major preliminary observations on the liquefaction-induced damages in the Meinong earthquake $\left(M_{L}=6.4\right)$. The severe damages to buildings centered on Huian and Sanmin Streets in Tainan City where the places were reclaimed fish or farm ponds with poor construction quality from many decades ago. To better understand the effect due to the soil liquefaction at these sites, the information provided by the in situ 13 Standard Penetration Test boreholes and 5 Cone Penetration Test soundings accompanying with the PGAs derived from the near seismographs was used to conduct the soil liquefaction evaluation by the Seed method (Seed et al. in J Geotech Eng ASCE 111(12):1425-1445, 1985) when subject to the Meinong earthquake. The liquefaction potential index (LPI) was then evaluated accordingly. From the results, it was found that the estimated damage severity was not consistent to the field conditions if the local site effect was not taken into account. To better reflect the site response in such sites, the sites'PGAs in the PGA contour map were multiplied by 1.5 times to quantify the amplification effects due to the soft geological condition. In addition, the PGAs based on other simple approaches were evaluated as well for comparison. Besides, the effects of fines content and magnitude scaling factor were also discussed in this paper. After that, several common simplified methods were also used to calculate the LPI when subject to the Meinong earthquake in order to evaluate the applicability of these simplified methods.
\end{abstract}

Keywords: Liquefaction, Building damage, Uncertainty, Meinong earthquake

\section{Introduction}

On February 6, 2015, a local magnitude $\left(M_{\mathrm{L}}\right) 6.4$ earthquake struck southern Taiwan. The epicenter was at $22.92^{\circ}$ north and $120.54^{\circ}$ east with a focal depth of $14.6 \mathrm{~km}$ according to the Taiwan Central Weather Bureau (CWB). The epicenter was near the town of Meinong in Kaohsiung City and thus was called Meinong earthquake. No significant damage was reported in the epicentral region. However, serious damages occurred approximately $30 \mathrm{~km}$ west of the epicenter in Tainan City. The collapse of the 16-story Wei Guan complex building (30 km from the epicenter) resulted in 115 deaths and caused the greatest public concern. Apart from this tragic

\footnotetext{
*Correspondence: chchlu@ncree.narl.org.tw

${ }^{1}$ National Center for Research on Earthquake Engineering, No. 200, Sec. 3, Xinhai Rd., Taipei 10668, Taiwan, ROC

Full list of author information is available at the end of the article
}

event, the liquefaction-induced damages also caused considerable concern. This paper presents major preliminary observations on the liquefaction-induced damage. The severe building damages centered on Huian and Sanmin Streets in Tainan City. From old geographical information, we know that these areas are fill reclamation from old fish or farm ponds, and it is not surprising that the construction of these reclaimed areas had poor quality control. Since seismic stations were far from these areas, there is some doubt as to the exact PGAs. To better understand the effect of site responses in these areas, this study used the several simplified approaches to consider site response analyses and quantify the amplification effects of the sites subject to the Meinong earthquake for comparison. After that, several common simplified methods with the information provided by 13 Standard Penetration Test (SPT) boreholes and 5 Cone Penetration Test $(\mathrm{CPT})$ soundings were used to estimate the liquefaction 
potential index (LPI) during the Meinong earthquake. The liquefaction evaluation results combined with the soil characteristics were used to explain the failure mechanism of the damaged buildings. It was also found that the estimated damage severity was not consistent with the field conditions if the local site effect was not taken into account, because this results in the underestimate of the PGA at the site. Besides, the performance of the simplified methods in moderate magnitude earthquake was reviewed based on the collected case histories. The sensitivity of fines content in liquefaction assessment was also evaluated.

\section{Liquefaction-induced damages to building structures}

Based on a field investigation by a survey team from the National Center for Research on Earthquake Engineering (NCREE), the locations of major liquefaction sites are shown in Fig. 1 along with the epicenter and the CWB seismic stations. The estimated peak ground accelerations range from 0.15 to $0.25 \mathrm{~g}$ in this general area. The major liquefaction sites include Annan (LI), Sinshih (L2), Wenhe (L3), Zhengju (L4), Dawan E (L5) and Xinhua (L6). The first four sites are residential areas and liquefaction led to different levels of structural damage. The last two are free-field sites located on farm land, and thus, no damage was reported. According to the definition of ground failure index (GFI) (Table 1) proposed by Bray and Stewart (2000), the most severely damaged areas were located at the Annan, Sinshih, Wenhe and Zhengju sites where substantial settlements and tilts of buildings are summarized in Table 2. In this paper, the liquefaction evaluation mainly focuses on the two most severely damaged areas in the Annan and Sinshih Districts. The distributions of the ground failure index for Annan and Sinshih Districts are shown in Fig. 2 along with the

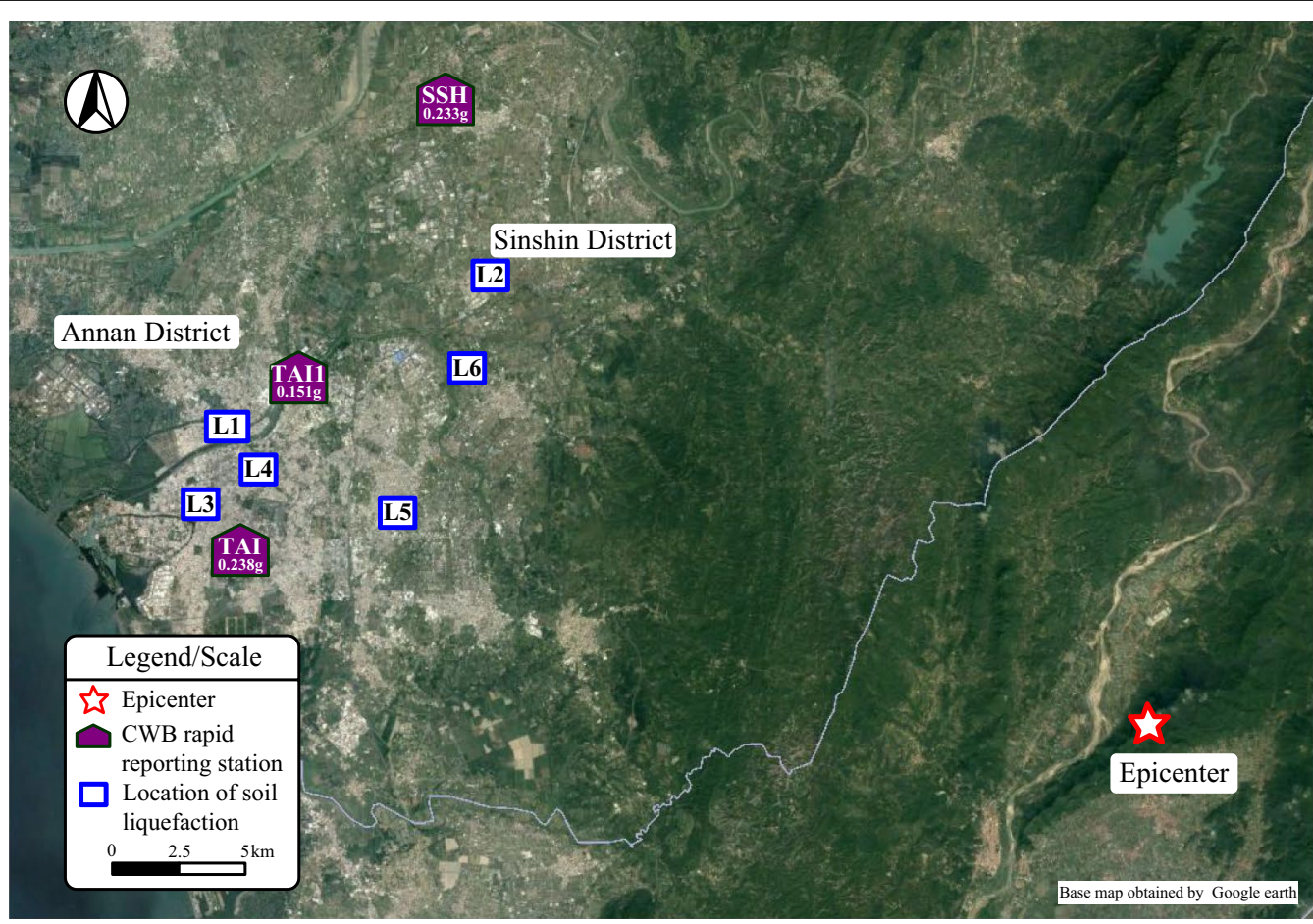

Fig. 1 Locations of liquefaction sites, epicenter and seismic stations

Table 1 Ground failure index (after Bray and Stewart 2000)

\begin{tabular}{lll}
\hline Index & Description & Interpretation \\
\hline GF0 & No observable ground failure & No settlement, tilt, lateral movement or sediment ejecta \\
GF1 & Minor ground failure & Settlement, $D<10 \mathrm{~cm}$; tilt $<1^{\circ} ;$ no lateral movements \\
GF2 & Moderate ground failure & $10 \mathrm{~cm}<D<25 \mathrm{~cm}$; tilt of $1^{\circ}-3^{\circ} ;$ small lateral movements $(<10 \mathrm{~cm})$ \\
GF3 & Significant ground failure & $D>25 \mathrm{~cm}$; tilt of $>3^{\circ}$; lateral movement $>25 \mathrm{~cm}$ \\
\hline
\end{tabular}


Table 2 Damage description of major liquefaction sites

\begin{tabular}{|c|c|c|}
\hline Location & Index & Description \\
\hline Annan & GF1 & The settlement of this area ranging from 10 to $20 \mathrm{~cm}$ mainly occurred at and around the building. The differential settlement \\
\hline Annan & GF2 & caused cracks between the building and road; meanwhile, the pipeline at the interface was destroyed \\
\hline Annan & GF3 & The building in this area seriously settled $(40-90 \mathrm{~cm})$ and tilted $\left(1^{\circ}-7^{\circ}\right)$. The road heaved much and had extensive sand boiling \\
\hline Sinshih & GF1 & The settlement of building is minor due to soil liquefaction \\
\hline Sinshih & GF2 & $\begin{array}{l}\text { The maximum settlement of column was about } 10 \mathrm{~cm} \text {. The maximum tilt of building is about } 1^{\circ} \text {. Boiling sand deposited in the } \\
\text { kitchen and ditch behind the building. The first floor slab heaved and cracked. The edge of road cracked and damaged the } \\
\text { water pipeline }\end{array}$ \\
\hline Sinshih & GF3 & $\begin{array}{l}\text { The area was fishpond before. The three-story building here is a two-span frame structure in long direction with a garage add-on } \\
\text { in front of house. Due to soil liquefaction, the column seriously settled and caused the indoor first floor slab heaving and crack- } \\
\text { ing much. The sand/mud boiling was obvious inside the house. Fire lanes heaved and sand deposited in the ditch. The road in } \\
\text { front of building heaved and the pipeline was damaged. The sand boiling could be observed everywhere }\end{array}$ \\
\hline Wenhe St. & GF2 & $\begin{array}{l}\text { The settlement of building was a few of centimeters. The first floor slab and road pavement had minor cracks. Sand boiling took } \\
\text { place nearby }\end{array}$ \\
\hline Wenhe St. & GF3 & $\begin{array}{l}\text { The maximum tilt and settlement of the building were } 4^{\circ} \text { and } 20 \mathrm{~cm} \text {, respectively. It could be found the sand boiling on the } \\
\text { surface of roads nearby }\end{array}$ \\
\hline Zhengju St. & GF1 & $\begin{array}{l}\text { The degree of soil liquefaction was slight. The differential settlement of building caused brick wall cracked, window railings } \\
\text { deformed, as well as road and floor slab cracked }\end{array}$ \\
\hline
\end{tabular}

positions of the geological investigation points. In Annan District, six buildings in Huian Street suffered serious damages and had been demolished based on the restoration principle. The No. 8 and No. 6 three-story buildings at Lane 161, Huian Street (Annan District), suffered the most severe damages as shown in Fig. 3. The No. 8 building settled $90 \mathrm{~cm}$ and tilted to $3^{\circ}$ toward west and $4^{\circ}$ toward south. The No. 6 building settled $60 \mathrm{~cm}$ and tilted $2^{\circ}$ toward west and $2^{\circ}$ toward south. Figure 4 shows the damage to No. 7 building at Alley 10, Lane 50, Sanmin Street (Sinshih District). It is found that the front part of the building is a garage and the back part is a main threestory RC structure. Since the garage is light and the main structure is heavy, the differential settlement occurred due to this uneven loading. It caused the damage to the walls of the garage. The damaged buildings in Sanmin Street are currently restored by jack and upright method.

\section{Post-earthquake investigations Geological investigation}

Based on the geological information provided by Central Geological Survey (CGS), the geological deposit of Tainan area belongs to Holocene alluvial. The liquefied areas in this earthquake were reclaimed fish or farm ponds from many decades ago. At that time, the quality of construction was poor. These reclamation areas were thought to have poor compaction, and the fill material used may have been of questionable quality.

To better understand the complex geological conditions of the liquefied sites, geotechnical borings and Seismic Cone Penetration Test (SCPT) soundings were conducted in the Annan and Sinshih Districts right after the earthquake. The locations of these investigation points are shown in Fig. 2. Many thin-walled tube samples were retrieved from the boreholes for performing undrained static and cyclic triaxial tests and resonant column tests.

The geological profiles based on the SPT and SCPT soundings in the Annan District are shown in Fig. 5. From the figure, the groundwater tables are shallow: 0.55$0.95 \mathrm{~m}$ below the ground surface. In terms of strength, the deposits can be roughly divided into two groups: one from 0 to $11 \mathrm{~m}$ and the other from 11 to $20 \mathrm{~m}$. The shallow deposits $(0-11 \mathrm{~m})$ consist of an uneven distribution of silty sand (SM), silt (ML) and clay (CL). Of these, the SM and ML soils are liquefiable. The SM soils have fines content of $16-43 \%$ with very low $N$ values $(<3.0)$. The ML soils have $N$ values of $2-8$ in general. It can be seen that the liquefaction resistances of SM and ML are poor. Given the high water table, this loose and non-cohesive geological material is quite sensitive to the process of liquefaction during earthquake. The CL soils have $N$ values of 1-2.5 in general. Due to the weak strength of the CL soils, the foundation bearing layer has difficulty providing sufficient bearing capacity for the surface structure once the adjacent SM and ML soils liquefy. Note that the soils near the ground surface have an unusually high $N$ value of 22 based on the $\mathrm{BH}$-A3 borehole record at the depth between 1.05 and $1.50 \mathrm{~m}$. This may be caused by the compaction of the base material due to the construction of road pavement. For the deposits below $11 \mathrm{~m}$, the strength is higher in general according to the SPT- $N$ values or cone penetration resistances $\left(q_{\mathrm{c}}\right)$, but some weak ML soils can still be found occasionally.

Figure 6 shows the geological profiles based on the SPT and SCPT soundings in the Sinshih District. The 

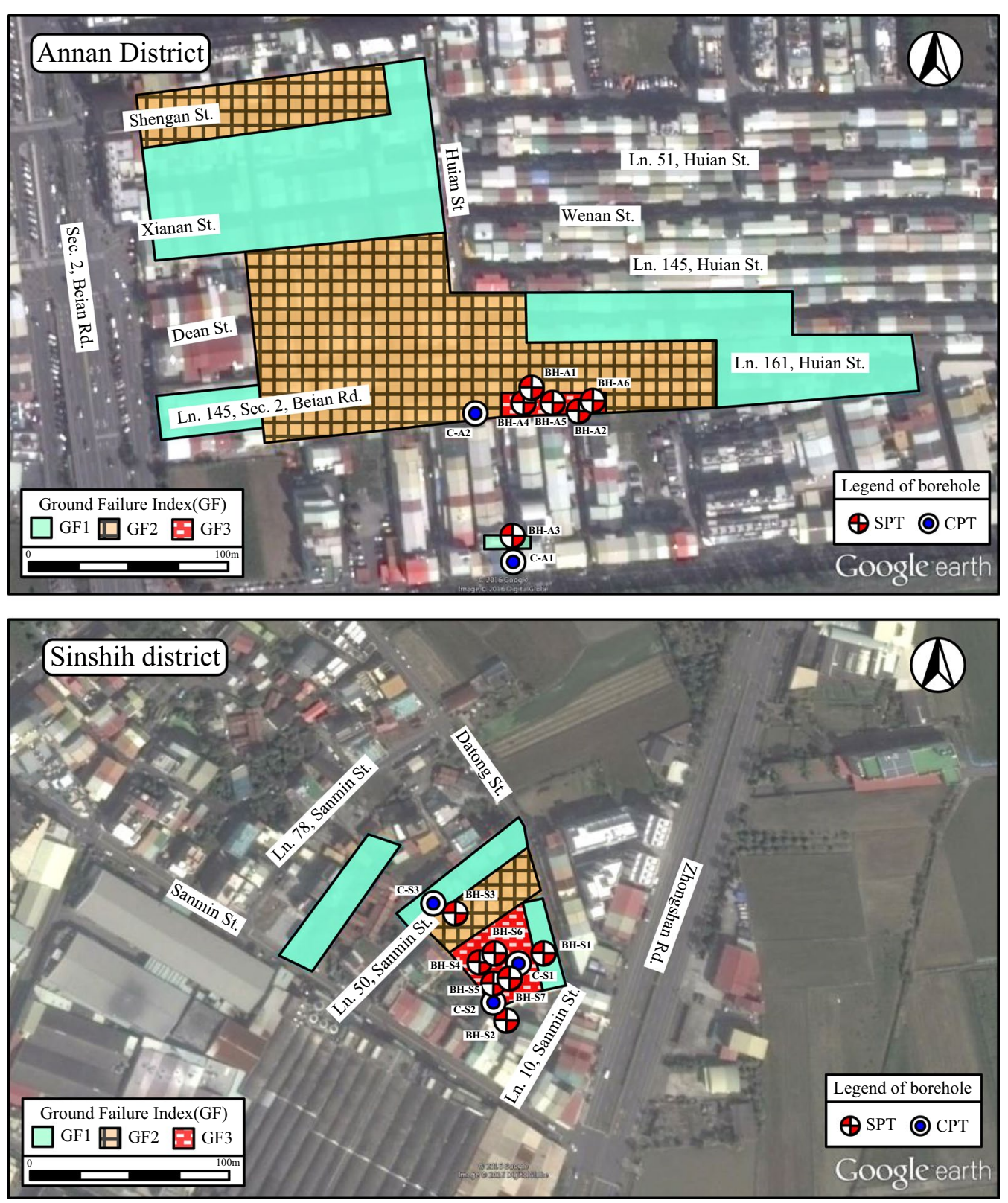

Fig. 2 Distributions of ground failure index for Annan and Sinshih Districts

water tables range from 0.55 to $0.86 \mathrm{~m}$ below the ground surface at Sanmin Street. The soils at shallow depths $(0-10 \mathrm{~m})$ consist of uneven distribution of silty sand (SM), silt (ML) and clay (CL). The SM soils have a fines content of $9-40 \%$ with $N$ values of $2-11$. The ML soils have $N$ values of 2-8 in general. Since the strengths of the liquefiable soils (SM and ML) are low, the evidence of soil liquefaction in this area can be easily observed when shaken by relatively larger ground motion. The CL soils have $N$ values of $1-9$ in general. Again, the CL soils are difficulty to provide sufficient bearing capacity to support the weight of the surface structure alone. The deeper deposits (11-20 m) mainly consist of ML and CL soils, whose strengths are greater than the ones at shallow depth.

\section{Evaluation of peak ground acceleration}

After the Taiwan Strong Motion Instrumentation Program (TSMPI), the urban areas of Taiwan are commonly dotted with seismographs, and the PGA can be easily 


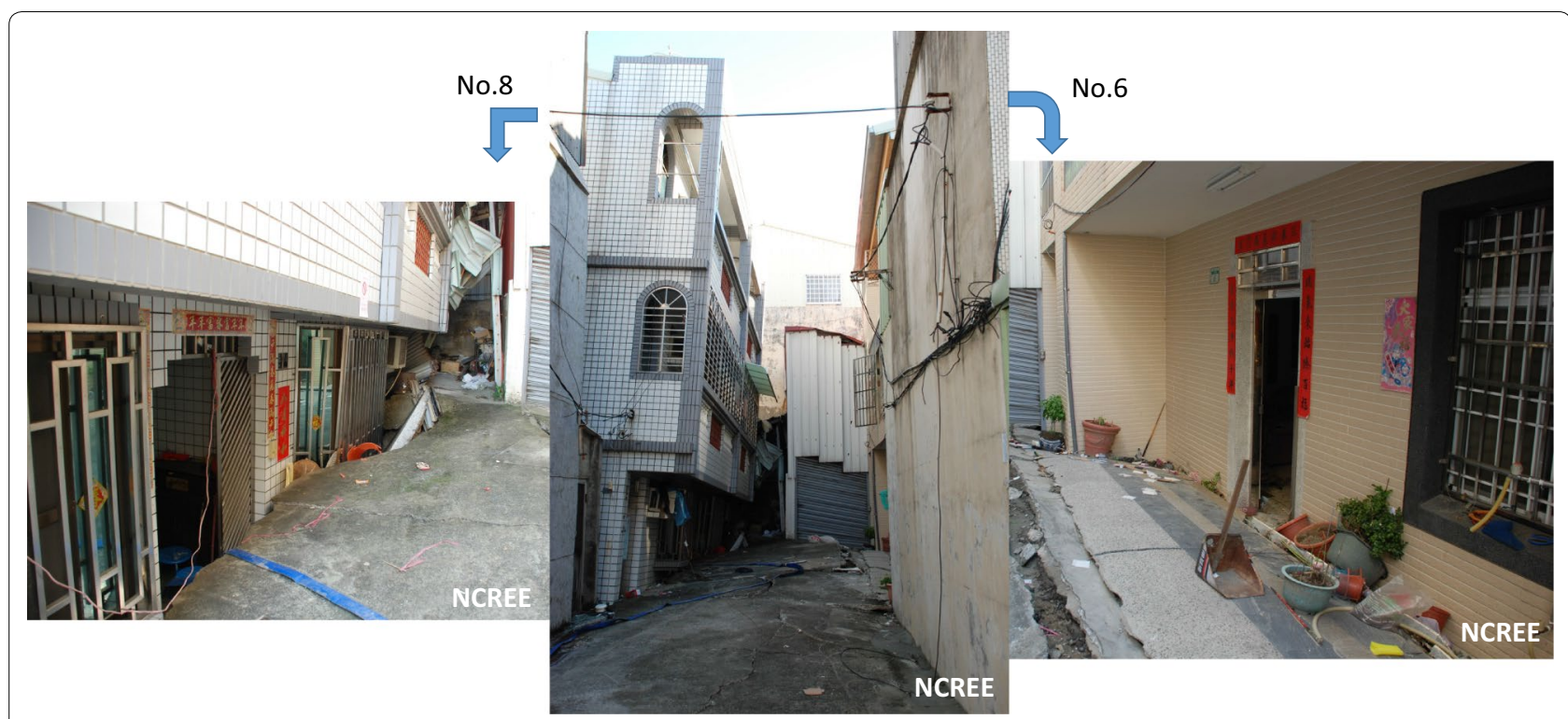

Fig. 3 Damages to No. 8 and 6 three-story buildings at Lane 161, Huian Street (Annan District)

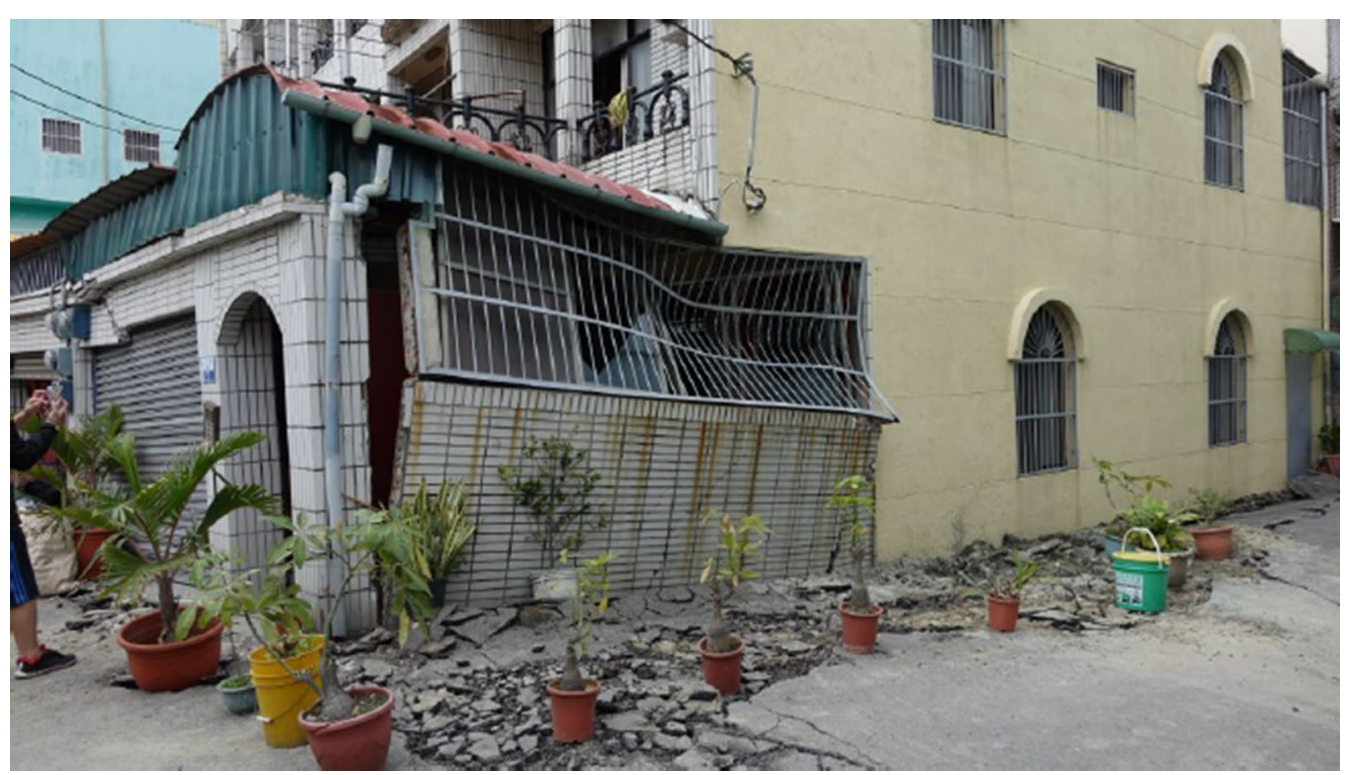

Fig. 4 Damage to No. 7 building at Alley 10, Lane 50, Sanmin Street (Sinshih District)

obtained from the near seismograph after earthquake in general. However, in this case, there is no seismograph near the sites with serious liquefaction condition during the Meinong earthquake. In other words, to obtain the PGAs on the liquefied site, several evaluation approaches should be adopted. Among them, the most straightforward one is to adopt the PGA from the closest seismograph. Note that the accuracy of the approach may be insufficient due the distance from the measured instrument to the concerned site. Another one is to first make the PGA contour map by the method of interpolation and extrapolation based on the information provided by the neighbor seismographs and then derive the PGA of the liquefied site from the map. In addition, the empirical attenuation law can also be used. It should be noted that the above approaches do not well consider the amplification of seismic ground motion during the upward propagation from the bedrock to ground surface, 


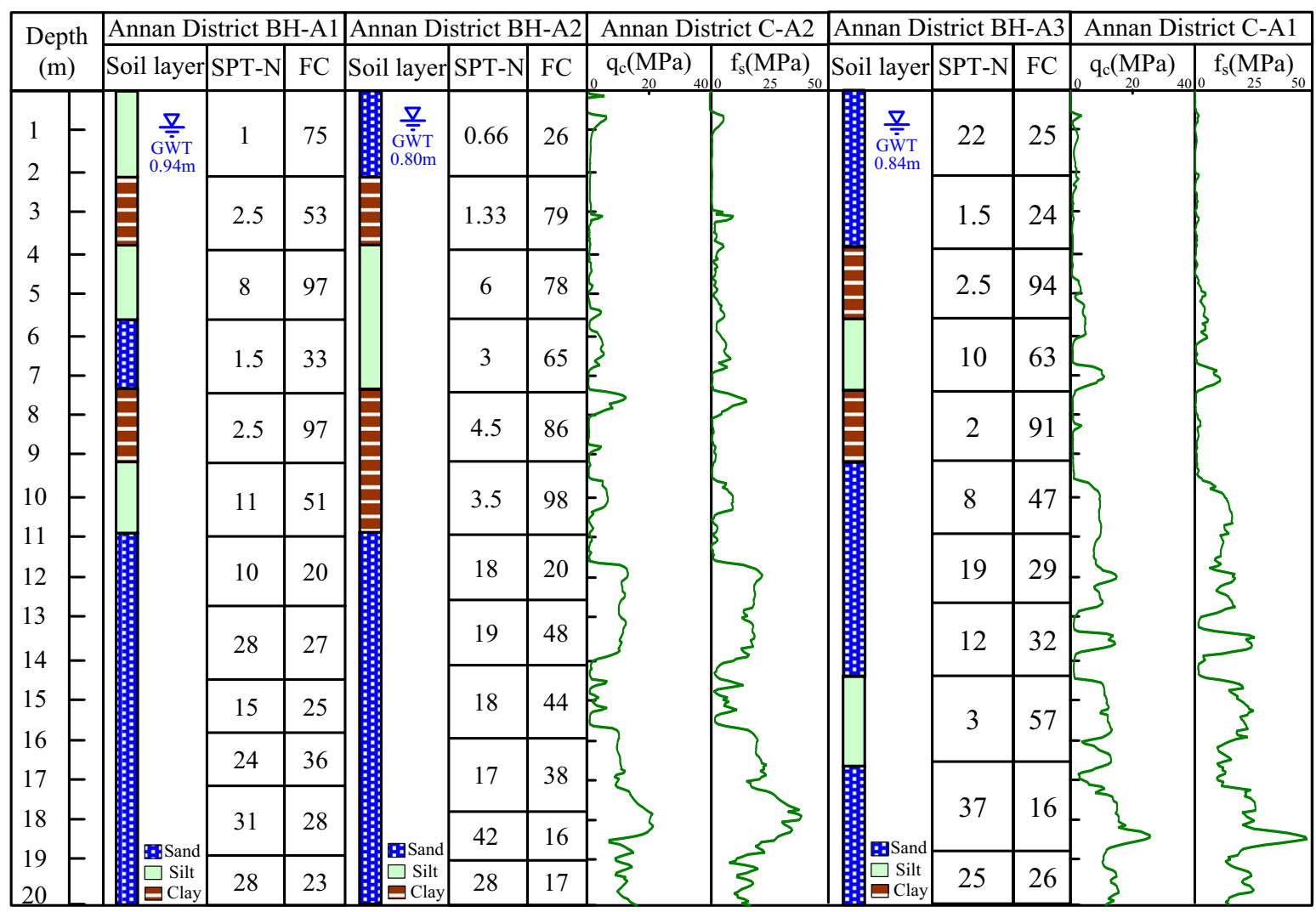

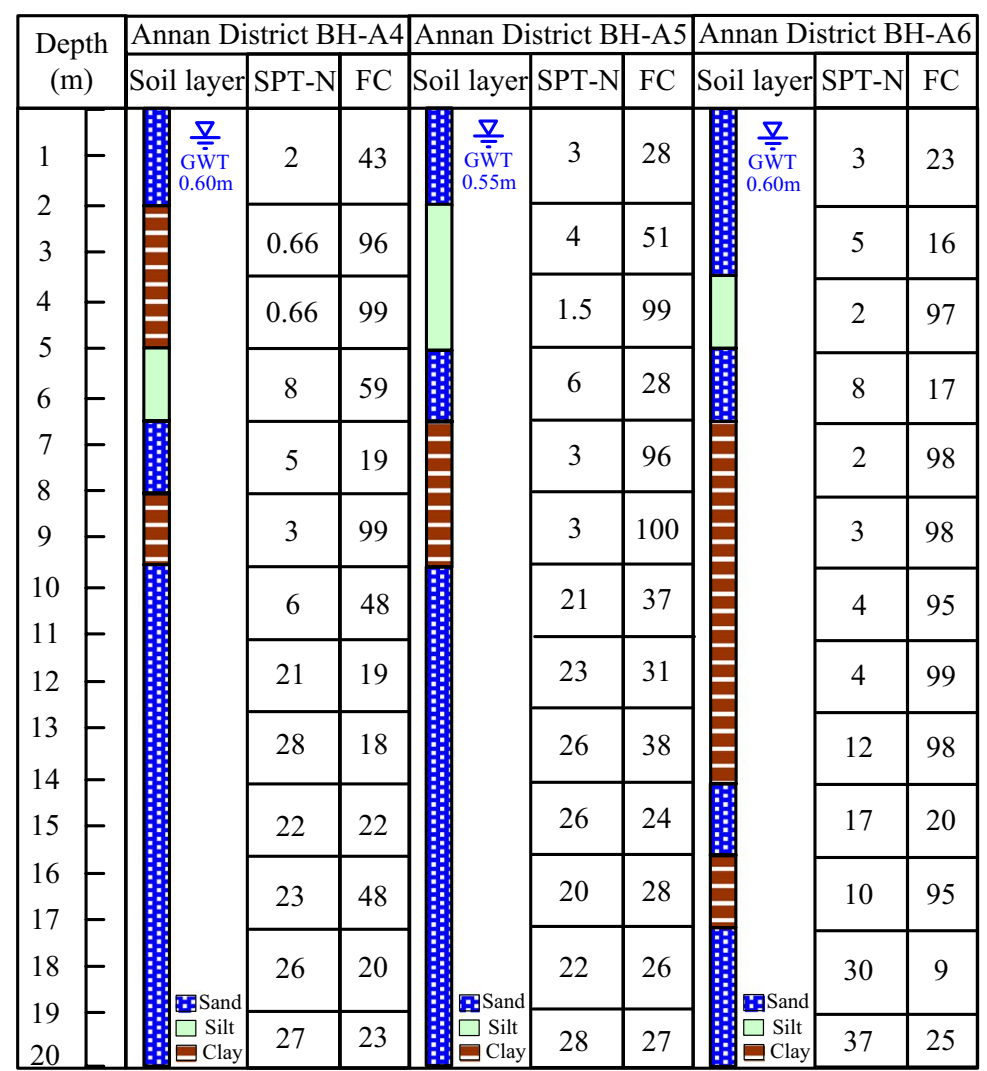

Fig. 5 Geological profiles of Annan District 

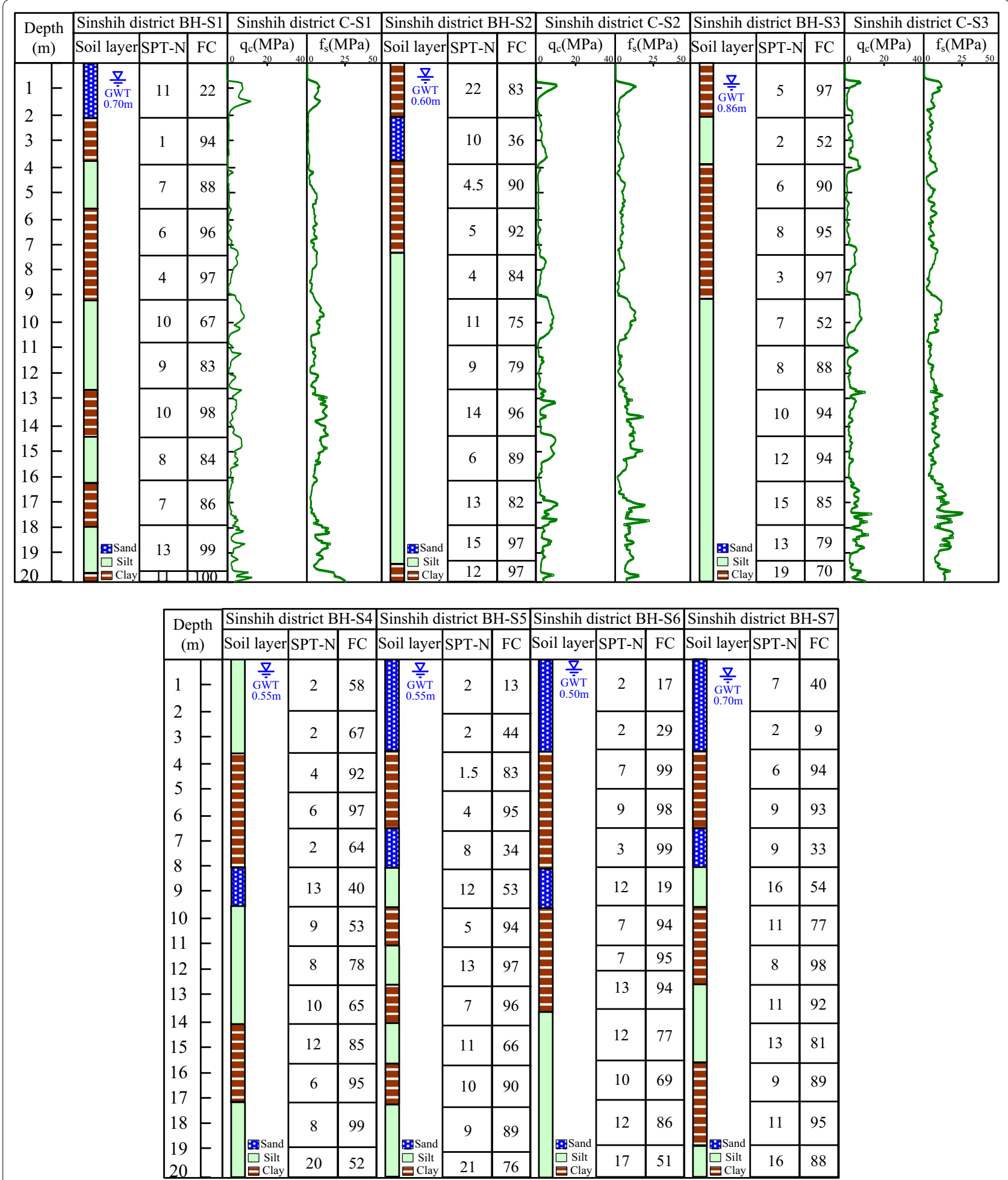

Fig. 6 Geological profiles of Sinshih District 
which implies that the effect of site response is ignored. However, the liquefaction sites in Huian and Sanmin Streets were man-made fill grounds in old water ponds. The PGA may be significantly amplified due to the loose backfill materials. Based on the "Design specifications of building foundations" (Construction and Planning Agency, MOI 2010), the acceleration amplification of the weakest ground (Class III) is 1.2, while the PGA of bedrock is smaller than $0.24 g$. In this case, the reclaimed land is thought to be much weaker than the weakest ground defined by the code and the PGA of the bed rock is smaller than $0.24 g$. The amplification factor higher than 1.2 is thought to be reasonable. Furthermore, according to analysis results of site response at soft ground by Idriss (1990), the PGA amplification factor is from 1.4 to 1.6, while the acceleration at bedrock is from 0.20 to $0.15 g$. Therefore, an average PGA amplification factor of 1.5 is assumed. The estimated PGA values in these liquefaction sites are listed in Table 3. It can be found the PGA from empirical attenuation law is the lowest and the PGA considering amplification effect is the largest.

\section{Soil liquefaction evaluation}

To determine the effect of soil liquefaction in severe liquefaction areas during the Meinong earthquake, the liquefaction potential index (LPI) proposed by Iwasaki et al. $(1978,1982,1984)$ was used to evaluate the liquefaction severity at each site. The equation for LPI is expressed as:

$$
\mathrm{LPI}=\sum_{i=1}^{\mathrm{NL}}(\Delta \mathrm{LPI})_{i}=\sum_{i=1}^{\mathrm{NL}} F_{i} \times w_{i} \times \Delta H_{i}
$$

where $N L$ is the number of soil layers, $F_{i}$ is the function of FS of the $i$ th layer defined in Eq. (2) and $w_{i}$ is the depth weighting factor $(=10-0.5 z \geq 0$, where $z$ is the depth in meters) which implies that the severity of surface manifestation of liquefaction is proportional to the proximity of the liquefied layer to the ground surface and there is no contribution from soils below $20 \mathrm{~m}$, and $\Delta H_{i}(\mathrm{~m})$ is the thickness of the ith layer which implies that the severity of liquefaction is proportional to the thickness of the liquefied layer.

$$
F_{i}= \begin{cases}1-\mathrm{FS}_{i} & \text { for } \quad 0 \leq \mathrm{FS}_{i}<1 \\ 0 & \text { for } \quad \mathrm{FS}_{i} \geq 1\end{cases}
$$

where $\mathrm{FS}_{i}$ is the safety factor of the $i$ th layer of a horizontal formation without surface structures. This definition of the variable $F_{i}$ implies that only soils with FS $<1$ contribute to the severity of liquefaction at the ground surface. Given these definitions, LPI can range from 0 for a site with no liquefaction potential to a maximum of 100 for a site where FS $=0$ over the entire soil column. Based on the calibration of LPI with field observations by Iwasaki et al. (1982, 1984), four different liquefaction levels are identified and given in Table 4.

Regarding the calculation of the factor of safety (FS) of a soil element in a free-field horizontal ground, the simplified method is usually employed in engineering practice. In the simplified method, liquefaction "loading" is expressed as cyclic stress ratio (CSR) and liquefaction "resistance" is expressed as cyclic resistance ratio (CRR), and the factor of safety can be expressed as CRR/CSR. In this paper, the classic simplified method, so-called the Seed method, is recommended, which was pioneered by Seed and Idriss (1971) and later refined by Seed and Idriss (1982) and Seed et al. (1985). With the evaluation of Hwang and Yung (2003) and Hwang et al. (2005, 2012), the better performance of the Seed method has been concluded and suggested for practical soil liquefaction evaluation. In the evaluation of the CSR, the peak ground acceleration (PGA) is a key factor and to adopt the PGA from the nearest seismograph is straightforward and was adopted first. Table 5 shows the LPI evaluation results of the 13 SPT boreholes in Annan and Sinshih Districts. The GFIs based on the field observation at the corresponding boreholes are also presented in Table 5 for comparison. It can be seen that five SPT boreholes are in GF3 liquefaction area and one in GF1 liquefaction area of the Annan District. There are six SPT boreholes in GF3 liquefaction area

Table 4 Relationship between LPI and the degree of liquefaction risk

\begin{tabular}{ll}
\hline Range of LPI & Description \\
\hline $\mathrm{LPI}=0$ & Liquefaction risk is very low \\
$0<\mathrm{LPI} \leqq 5$ & Liquefaction risk is low \\
$5<\mathrm{LPI} \leqq 15$ & Liquefaction risk is high \\
$15<\mathrm{LPI}$ & Liquefaction risk is very high \\
\hline
\end{tabular}

Table 3 Estimated horizontal peak ground accelerations

\begin{tabular}{lll}
\hline PGA estimation method & Annan District $(\boldsymbol{g})$ \\
\hline Referring to the nearest seismograph & $0.168($ TAl) \\
PGA contour map (NCREE 2016) & 0.152 \\
Empirical attenuation model (Jean et al. 2006) & 0.128 \\
1.5 times the PGA of contour map (roughly consider site effect) & 0.196 \\
\hline
\end{tabular}


Table 5 LPI evaluation results of the Annan and Sinshih Districts

\begin{tabular}{|c|c|c|c|}
\hline Borehole & LPI & Liquefaction risk & GFI ranked by field observation (after Bray and Stewart 2000) \\
\hline \multicolumn{4}{|c|}{ Analyzed results of Annan District with the $P G A=0.168 \mathrm{~g}$ derived from TAl station } \\
\hline $\mathrm{BH}-\mathrm{A} 1$ & 8.6 & High & GF3 \\
\hline $\mathrm{BH}-\mathrm{A} 2$ & 10.7 & High & GF3 \\
\hline $\mathrm{BH}-\mathrm{A} 3$ & 8.4 & High & GF1 \\
\hline $\mathrm{BH}-\mathrm{A} 4$ & 2.9 & Low & GF3 \\
\hline $\mathrm{BH}-\mathrm{A} 5$ & 5.0 & Low & GF3 \\
\hline $\mathrm{BH}-\mathrm{A} 6$ & 4.1 & Low & GF3 \\
\hline Borehole & LPI & Liquefaction risk & GFI ranked by field observation (after Bray and Stewart 2000) \\
\hline \multicolumn{4}{|c|}{ Analyzed results of Sinshih District with the $P G A=0.233 \mathrm{~g}$ derived from SSH station } \\
\hline $\mathrm{BH}-\mathrm{S} 1$ & 5.7 & High & GF3 \\
\hline $\mathrm{BH}-\mathrm{S} 2$ & 8.6 & High & GF3 \\
\hline $\mathrm{BH}-\mathrm{S} 3$ & 12.5 & High & GF2 \\
\hline $\mathrm{BH}-\mathrm{S} 4$ & 13.6 & High & GF3 \\
\hline $\mathrm{BH}-\mathrm{S} 5$ & 14.1 & High & GF3 \\
\hline $\mathrm{BH}-\mathrm{S} 6$ & 13.1 & High & GF3 \\
\hline $\mathrm{BH}-\mathrm{S} 7$ & 8.9 & High & GF3 \\
\hline
\end{tabular}

and one in GF2 liquefaction area of the Sinshih District. To the GF3 area, the LPI was thought to be quite larger than 15 , which means liquefaction risk is "very high," before the liquefaction evaluation due to its serious liquefaction from field observation. However, from the LPI evaluation results of Annan District, it can be seen that the evaluated LPIs range from 2.9 to 10.7 , and the liquefaction risk in this area is just "low" or "high." Except the BH-A3 borehole, the results of the other boreholes do not comply with serious liquefaction condition from field observation. Similar to the Annan District, the evaluated LPIs of the boreholes in GF3 area of Sinshih District range from 5.7 to 14.1, which the liquefaction risk is just "high." Comparing with the field liquefaction evidences, the above evaluated LPIs of the both sites seem to be underestimated and not to reflect the serious liquefaction condition. The reasons may be deduced from several factors with unsuitable estimations due to the high uncertainty. It should be noted that due to the extreme site effect and lacking seismograph near the studied site, the accuracy of the PGA derived from the nearest seismograph is doubt. The uncertainty due to the different PGA evaluation will be discussed in the following section. Besides, other uncertainty factors such as the effect of fines content, magnitude scaling factor and different simplified methods will be also addressed.

\section{Effect of uncertainty}

\section{The peak ground acceleration}

The assessment of soil liquefaction potential by simplified method is normally regarded as a simple and straightforward job. However, due to the lack of seismograph at the liquefied sites in these cases, the estimates of the peak ground acceleration (PGA) become uncertain due to extreme site effect on the land reclamations from old fish or farm ponds. The estimated PGA values listed in Table 3 were used for the soil liquefaction evaluation by the Seed method. The results are given in Table 6 . It can be seen that only the case that considered the amplification effect due to the site characteristics of the reclamations can yield the LPIs that are approximately comparable with the field observation. The LPIs of the other cases are too low to reflect the serious liquefaction condition from field observation. Since the liquefied site is reclaimed from old fish or farm ponds by the material with poor quality control, the PGAs with considering the site response of the reclamations were thought to be more rational than the rest. Thus, the PGA of $0.228 g$ in Annan District and the PGA of 0.294 $g$ in Sinshih District would be used for the following analyses. It should be noted that the evaluated PGAs with considering the amplification effect are based on the authors' assumption. To obtain more accurate PGA on the studied sites, more complicated analysis is recommended for next phase.

\section{The effect of the fines content}

From the samples of the SPT boreholes, the soil material in these sites has high fines content with low plasticity index (PI). It was argued the effect of fines content on the increase in the CRR in this kind of soil material. Therefore, the scenario adopted in "Soil liquefaction evaluation" section was re-evaluated by the same simplified method with ignoring the contribution of the fines 
Table 6 The evaluated LPI subject to the PGAs evaluated by different approaches

\begin{tabular}{|c|c|c|c|c|}
\hline \multirow[t]{3}{*}{ Borehole } & \multicolumn{4}{|c|}{ PGA (evaluation approach) } \\
\hline & $\begin{array}{l}0.128 g \\
\text { (Attenu. model) }\end{array}$ & $\begin{array}{l}0.152 g \\
\text { (Contour map) }\end{array}$ & $\begin{array}{l}0.168 g \\
\text { (Seismograph) }\end{array}$ & $\begin{array}{l}0.228 g \\
\text { (Amp. effect) }\end{array}$ \\
\hline & \multicolumn{4}{|l|}{ LPI } \\
\hline \multicolumn{5}{|c|}{ Annan District } \\
\hline $\mathrm{BH}-\mathrm{A} 1$ & 4.1 & 7.1 & 8.6 & 14.8 \\
\hline $\mathrm{BH}-\mathrm{A} 2$ & 6.5 & 9.3 & 10.7 & 17.3 \\
\hline $\mathrm{BH}-\mathrm{A} 3$ & 4.9 & 7.2 & 8.4 & 13.7 \\
\hline $\mathrm{BH}-\mathrm{A} 4$ & 0.0 & 1.3 & 2.9 & 10.3 \\
\hline $\mathrm{BH}-\mathrm{A} 5$ & 2.8 & 4.2 & 5.0 & 14.2 \\
\hline $\mathrm{BH}-\mathrm{A} 6$ & 1.7 & 3.3 & 4.1 & 12.9 \\
\hline \multirow[t]{3}{*}{ Borehole } & \multicolumn{4}{|c|}{ PGA (evaluation approach) } \\
\hline & $\begin{array}{l}0.140 \mathrm{~g} \\
\text { (Attenu. model) }\end{array}$ & $\begin{array}{l}0.194 \mathrm{~g} \\
\text { (Contour map) }\end{array}$ & $\begin{array}{l}0.233 g \\
\text { (Seismograph) }\end{array}$ & $\begin{array}{l}0.294 g \\
\text { (Amp. effect) }\end{array}$ \\
\hline & LPI & & & \\
\hline \multicolumn{5}{|c|}{ Sinshih District } \\
\hline $\mathrm{BH}-\mathrm{S} 1$ & 0.0 & 0.8 & 5.7 & 11.5 \\
\hline $\mathrm{BH}-\mathrm{S} 2$ & 1.5 & 5.3 & 8.6 & 14.2 \\
\hline $\mathrm{BH}-\mathrm{S} 3$ & 2.1 & 8.2 & 12.5 & 18.5 \\
\hline $\mathrm{BH}-\mathrm{S} 4$ & 1.8 & 8.5 & 13.6 & 20.9 \\
\hline $\mathrm{BH}-\mathrm{S} 5$ & 3.9 & 10.4 & 14.1 & 20.8 \\
\hline $\mathrm{BH}-\mathrm{S} 6$ & 3.7 & 10.4 & 13.1 & 19.0 \\
\hline $\mathrm{BH}-\mathrm{S} 7$ & 5.9 & 7.9 & 8.9 & 12.7 \\
\hline
\end{tabular}

content. In this soil liquefaction evaluation, the PGAs with considering the site effect were used due to the comment of "The peak ground acceleration" section. Table 7 shows the comparison between the results by the Seed method and the one without the consideration of FC. It can be seen that if the contributions of fines for SM and ML are neglected, all the predicted LPIs will become significantly larger and closer to the field damage conditions. From the results, the contribution of fines content is significant, and it is suggested to carefully study the increase in CRR due to the fines content with low plasticity index $(\mathrm{PI})$.

\section{The effect of the magnitude scaling factor}

The duration of the earthquake has a great influence on the amount of the generated excess pore water pressure. In liquefaction evaluation, the influence of the earthquake duration is replaced by an equivalent loading cycles. The larger the earthquake magnitude, the more the number of the loading cycles, the smaller the cyclic resistance ratio (CRR). The Seed method was developed based on the case histories with earthquake magnitude close to 7.5 . If the earthquake magnitude is different from 7.5, the magnitude scaling factor (MSF) should be used to modify the
CRR, especially when the earthquake magnitude of the Meinong earthquake is just 6.4. In practice, the MSF $=1$ for an earthquake with a moment magnitude $M_{\mathrm{w}}=7.5$. The MSF is greater than 1 when $M_{\mathrm{w}}<7.5$ and less than 1 when $M_{\mathrm{w}}>7.5$. In the original Seed method, the MSF suggested by Seed and Idriss (1982) is employed. It is of interest the performance of the MSF in the Seed method in moderation magnitude earthquake. In this section, the Seed method with several MSFs would be evaluated. Besides the MSF suggested by Seed and Idriss (1982), the other two common used MSFs including Idriss (1997) and Andrus and Stokoe (1997) were tested. Please refer to Youd and Idriss (1997) for the detailed background of the tested MSFs. The PGAs recommended by Sect. 5.1 were used. Table 8 shows the LPIs evaluated by the Seed method with different MSFs. From the results, the MSF suggested by Seed and Idriss (1982) is most conservative, and the MSF suggested by Idriss (1997) is followed by the one suggested by Andrus and Stokoe (1997). Figures 7 and 8 demonstrate the evaluated LPIs comparing with LPI $=15$ and 5 . Because the locations of the most boreholes are located on serious liquefaction sites (GF3), the evaluated LPIs larger than 15 are thought to be more rational. In light of this view, the MSF suggested by Seed 
Table 7 The effect on LPI evaluation due to the fines content

\begin{tabular}{lll}
\hline Borehole & $\begin{array}{l}\text { LPI } \\
\text { (by default of the Seed method) }\end{array}$ & $\begin{array}{l}\text { LPI } \\
\text { (no contribution of FC) }\end{array}$ \\
\hline Analyzed results of Annan District with the $P G A=0.2289$ & \\
BH-A1 & 14.8 & 33.2 \\
BH-A2 & 17.3 & 29.7 \\
BH-A3 & 13.7 & 28.6 \\
BH-A4 & 10.3 & 24.2 \\
BH-A5 & 14.2 & 30.1 \\
BH-A6 & 12.9 & 26.1 \\
\hline Borehole & LPI & LPI \\
& (by default of the Seed method) & (no contribution of FC) \\
\hline Analyzed results of Sinshih District with the PGA=0.294g derived from SSH station & \\
BH-S1 & 11.5 & 21.4 \\
BH-S2 & 14.2 & 29.9 \\
BH-S3 & 18.5 & 30.9 \\
BH-S4 & 20.9 & 36.8 \\
BH-S5 & 20.8 & 35.2 \\
BH-S6 & 19.0 & 29.7 \\
BH-S7 & 12.7 & 22.4 \\
\hline
\end{tabular}

Table 8 The effect on LPI evaluation due to the MSF

\begin{tabular}{|c|c|c|c|c|}
\hline \multirow[t]{3}{*}{ Borehole } & \multicolumn{3}{|c|}{ Method to considered MSF } & \multirow[t]{3}{*}{$\Delta \mathrm{LPI}$} \\
\hline & Seed and Idriss (1982) & Idriss (1997) & Andrus and Stokoe (1997) & \\
\hline & \multicolumn{3}{|l|}{ LPI } & \\
\hline \multicolumn{5}{|c|}{ Analyzed results of Annan District with the $P G A=0.228 \mathrm{~g}$ derived from TAl station } \\
\hline $\mathrm{BH}-\mathrm{A} 1$ & 14.8 & 10.4 & 8.5 & 6.3 \\
\hline $\mathrm{BH}-\mathrm{A} 2$ & 17.3 & 12.7 & 10.6 & 6.7 \\
\hline $\mathrm{BH}-\mathrm{A} 3$ & 13.7 & 10.1 & 8.4 & 5.3 \\
\hline $\mathrm{BH}-\mathrm{A} 4$ & 10.3 & 5.5 & 2.7 & 7.6 \\
\hline $\mathrm{BH}-\mathrm{A} 5$ & 14.2 & 6.3 & 4.9 & 9.3 \\
\hline $\mathrm{BH}-\mathrm{A} 6$ & 12.9 & 5.2 & 4.0 & 8.9 \\
\hline \multirow[t]{3}{*}{ Borehole } & \multicolumn{3}{|c|}{ Method to considered MSF } & \multirow[t]{3}{*}{$\Delta \mathrm{LPI}$} \\
\hline & Seed and Idriss (1982) & Idriss (1997) & Andrus and Stokoe (1997) & \\
\hline & LPI & & & \\
\hline \multicolumn{5}{|c|}{ Analyzed results of Sinshih District with the $P G A=0.294 \mathrm{~g}$ derived from SSH station } \\
\hline $\mathrm{BH}-\mathrm{S} 1$ & 11.5 & 6.3 & 3.3 & 8.2 \\
\hline $\mathrm{BH}-\mathrm{S} 2$ & 14.2 & 9.2 & 6.8 & 7.4 \\
\hline $\mathrm{BH}-\mathrm{S} 3$ & 18.5 & 13.2 & 10.5 & 8.0 \\
\hline $\mathrm{BH}-\mathrm{S} 4$ & 20.9 & 14.5 & 11.0 & 9.9 \\
\hline BH-S5 & 20.8 & 14.6 & 12.2 & 8.6 \\
\hline $\mathrm{BH}-\mathrm{S} 6$ & 19.0 & 13.6 & 11.9 & 7.1 \\
\hline $\mathrm{BH}-\mathrm{S} 7$ & 12.7 & 9.2 & 8.4 & 4.3 \\
\hline
\end{tabular}

Seed and Idriss (1982) suggested MSF $=\left(M_{\mathrm{w}} / 7.5\right)^{-1.11}$

Idriss (1997) suggested MSF $=\left(M_{\mathrm{w}} / 7.5\right)^{-2.56}$

Andrus and Stokoe (1997) suggested MSF $=\left(M_{\mathrm{w}} / 7.5\right)^{-3.3}$ 


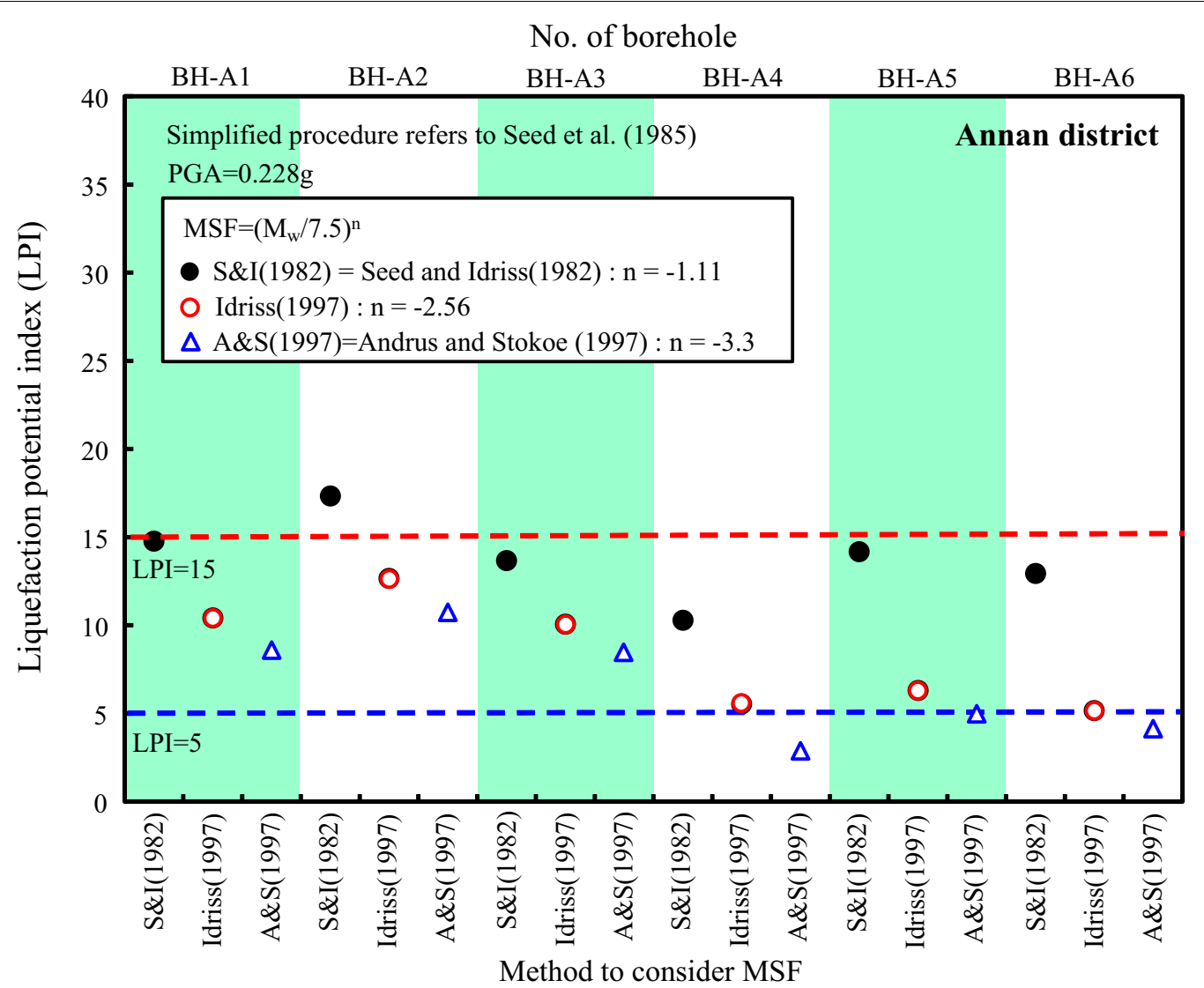

Fig. 7 Evaluated LPIs for the Annan District with considering different MSFs

and Idriss (1982) is considered to be more rational for the Seed method.

\section{The variation due to the different simplified methods}

Since LPI is evaluated from the obtained factors of safety (FS) to predict the potential of liquefaction to cause damage at the surface level, it should be noted that the evaluation by different simplified methods will result in different FS even if the borehole data are all the same. To quantify the variation of LPIs from different simplified methods, other common SPT-based and CPT-based simplified methods were also used in this study. Besides the classic Seed method, the other considered SPT-based simplified methods are the JRA method (Japanese Road Association 1996), the NCEER method (Youd and Idriss 1997), the AIJ method (Architecture Institute of Japanese 2009) and the HBF method (Hwang et al. 2012). The CPT-based simplified methods are the NCEER method (Youd and Idriss 1997) and the Juang's method (Juang et al. 2008). Figures 9 and 10 show the evaluated LPIs for Annan and Sinshih Districts by different simplified methods and estimated
PGAs for the SPT boreholes and CPT soundings. From the figures, we can see that the estimated PGAs have the largest influence on the LPI. The larger the PGA, the larger the LPI. The evaluated LPI results using the estimated PGAs considering amplification effect are closer to the damage conditions in the field. On the contrary, the use of PGA by the empirical attenuation law predicts no damage.

Among the SPT-based methods, the JRA and Seed methods are more conservative and the AIJ method is the least conservative. The NCEER and HBF methods are in between. The predicted LPIs by the JRA and Seed methods are more consistent with the damage conditions in the field. However, it should still be noted that the JRA method did not consider the magnitude scaling factor. Although the results evaluated by the JRA method are comparable with field observations, we suggest that the applicability of the method with other earthquake magnitudes should be checked carefully. The CPT-based methods generally predict a larger LPI than the SPT methods. Among the CPT-based methods, Juang's method is more conservative than the NCEER method. 


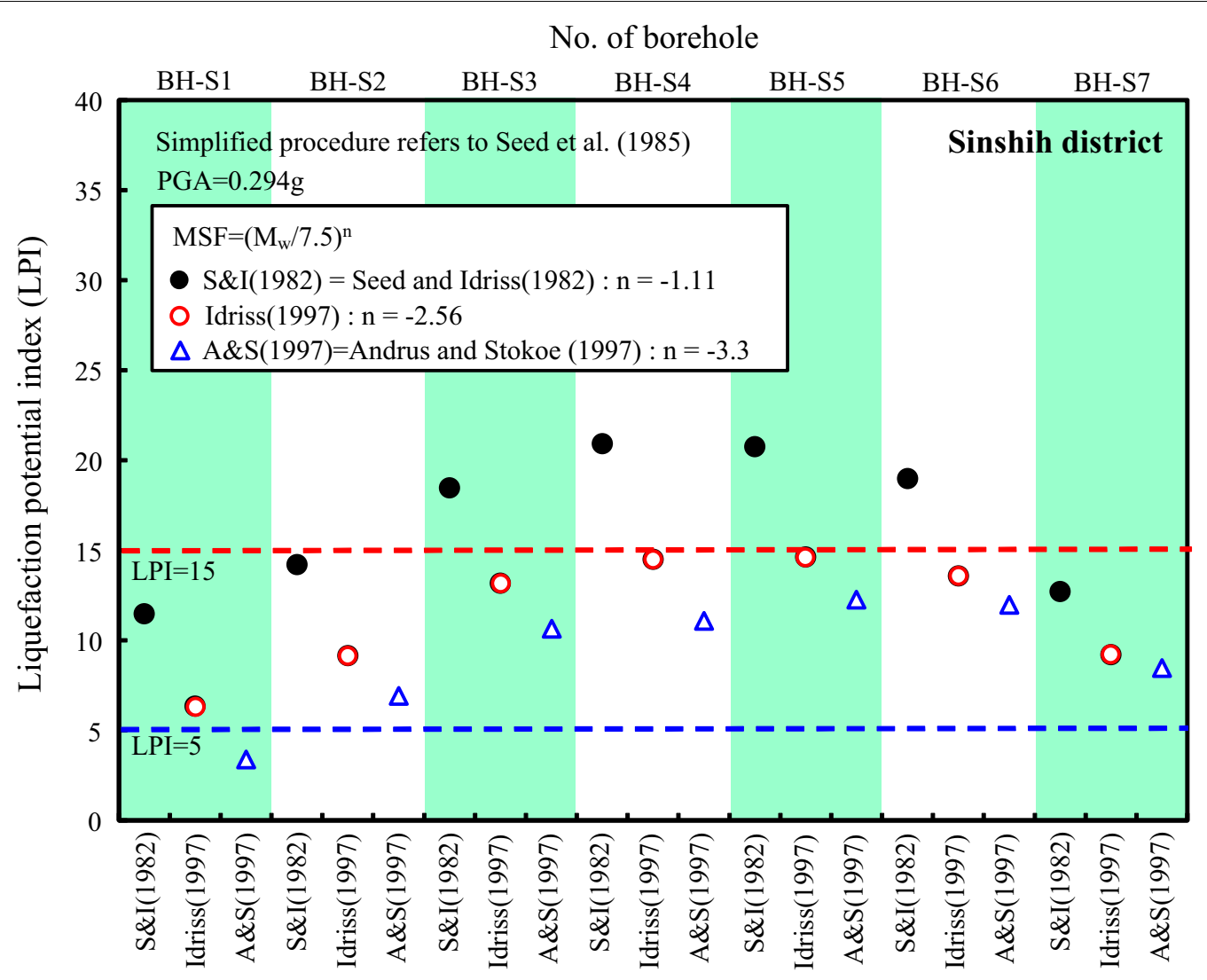

Method to consider MSF

Fig. 8 Evaluated LPIs for the Sinshih District with considering different MSFs

\section{Conclusion}

This paper discussed the liquefaction-induced damage to buildings that occurred during the Meinong earthquake. From site investigations, we determined that the formations of the liquefied sites always exhibit a very soft clay layer below the saturated sandy soils. The foundation load is mainly supported by the sandy soils and a preshear (deviatoric) stress existing in the foundation soil of the footing before earthquake. The soil is easier to reach the failure state due to the additional shear force and the generation of the excess pore water pressure triggered by the earthquake excitation and cause large settlement and deformation. During the shaking of the earthquake, the excess pore water pressure is generated and decreased the strength of the saturated sandy soils. When the softened sandy soils beneath the spread foundation cannot bear the deviatoric stress induced by the loading of the surface building as well as the additional shear force due to the seismic loading, the foundation bearing layer will be squeezed out laterally and upward. Then, the foundation load is transferred to the soft clay beneath the saturated sandy soils, which induces more settlement of the building. Note that if the weight of the surface building is uneven like the case shown in Fig. 4, the differential settlement can be observed in case of the foundation bearing layer being liquefied during earthquakes.

The soil liquefaction evaluation using the Seed method seemed to underestimate the degree of damage observed in the field if several uncertainties were not taken into account. The discussion shows that the liquefaction assessment is not a simple job and highlights some issues worth studying in the future. Based on the results, the site response should be carefully evaluated, especially where the site has been reclaimed from old farm and fishponds. It should be noted that the site effect is roughly estimated using a certain degree of engineering judgment by the authors. More advanced tools such as the equivalent linear-based SHAKE or the FDM-based FLAC programs are suggested to conduct the seismic response analyses for the sites. The mentioned programs have good performance to derive seismic response with considering the dynamic nonlinear properties of the soil medium under small to medium strain levels (Idriss and Sun, 1992; Rayhani et al., 2008; Itasca 2011). Since the Meinong 

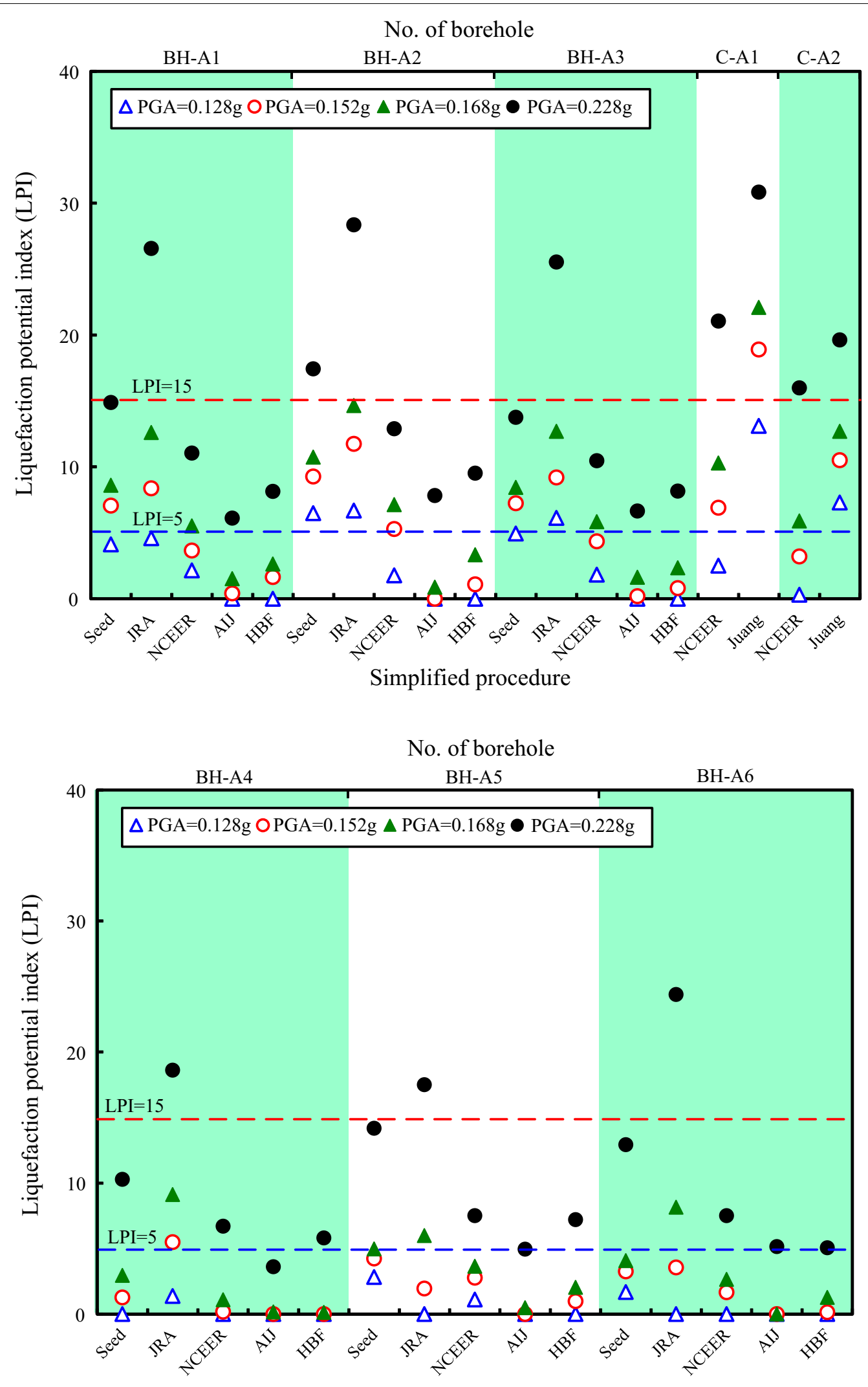

Simplified procedure

Fig. 9 Evaluated LPI for the Annan District by different simplified methods and PGAs 
No. of borehole

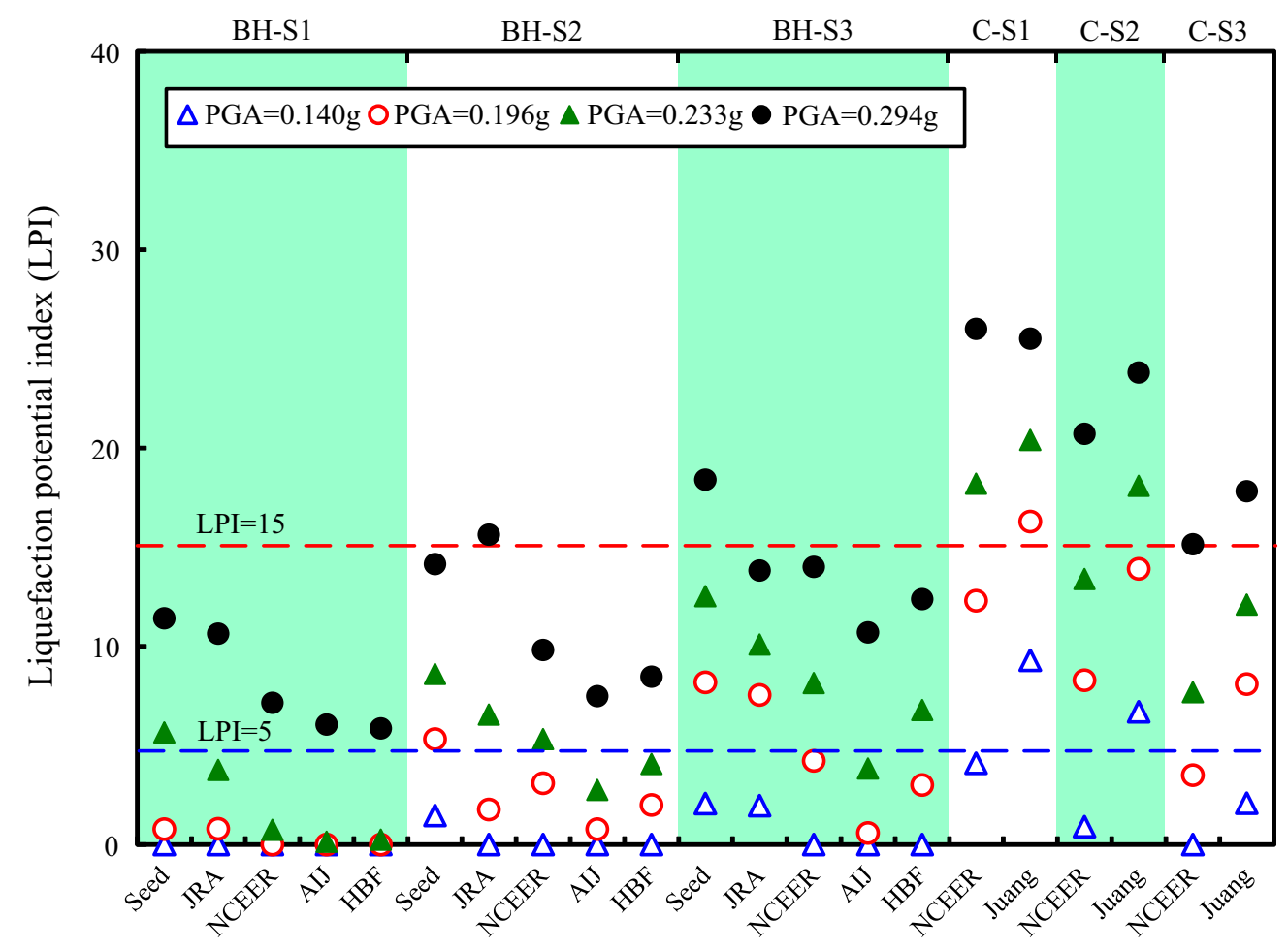

Simplified procedure

No. of borehole

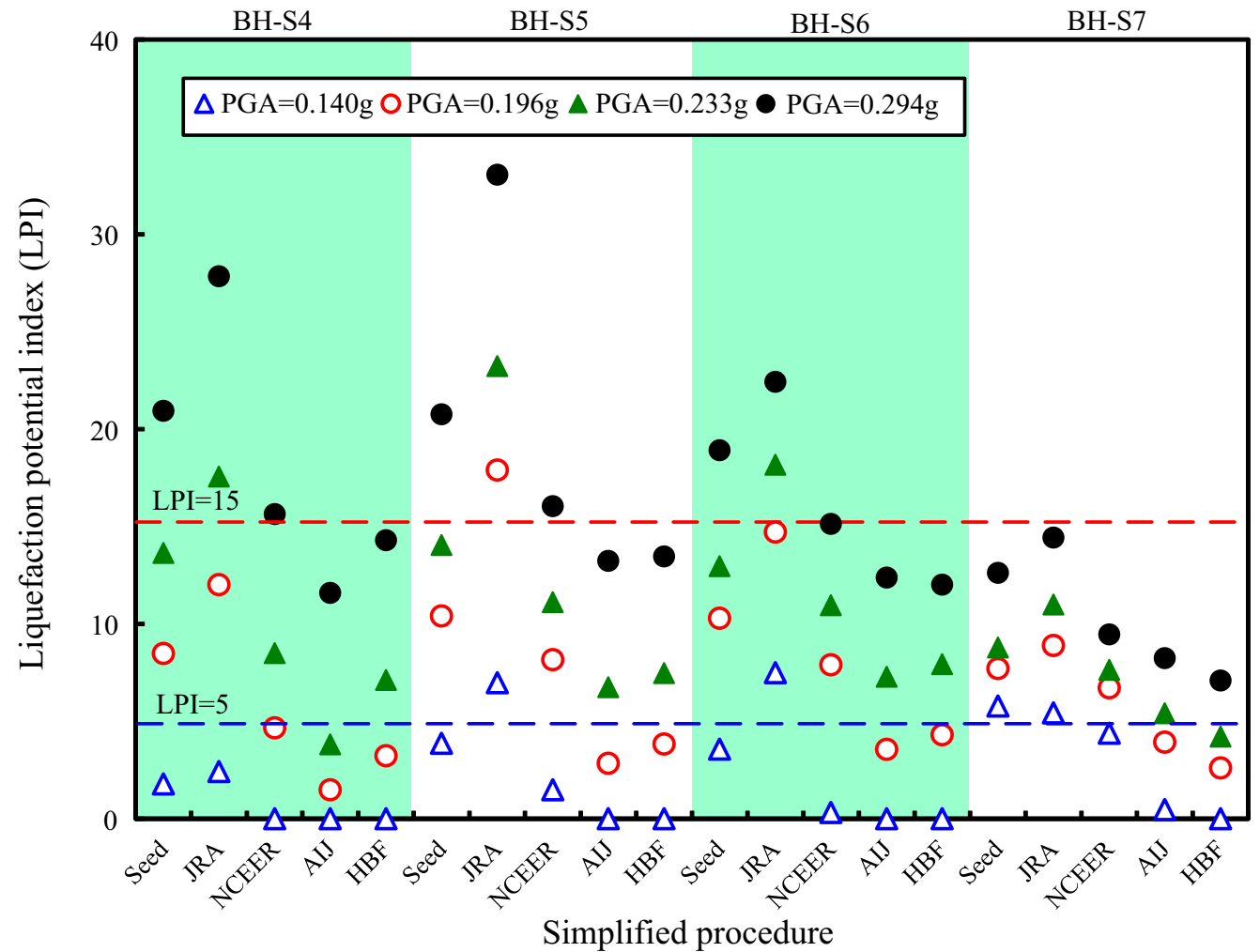

Fig. 10 Evaluated LPI for the Sinshih District by different simplified methods and PGAs 
earthquake $\left(M_{\mathrm{L}}=6.4\right)$ is a small to moderate earthquake, the determined PGAs by the programs for these sites will be more accurate and can be used to further review the rationality of the estimated PGAs in this study.

In the uncertainty discuss for the contribution of fines content, an extreme conservative assumption was made to evaluate the CRR contribution of fines content with low PI. From the results, if the effect of FC for SM and ML is neglected, all the predicted LPIs become significantly larger and closer to the field damage conditions. It is recommended to better understand the CRR contribution of the fines with low PI.

Regarding the suitability of the MSF for the Seed method, the MSF suggested by Seed and Idriss (1982) is suggested since the evaluation results are more comparable with field observation. In this paper, other simplified methods were also adopted. The predicted LPIs by the JRA and the Seed methods are more consistent to the damage conditions in the field. Note that the user of the JRA method should be aware that the method does not take the MSF into account. Except the Seed and JRA methods, the evaluated LPIs by other methods predict only light to moderate liquefaction-induced damages which are not consistent to the severe GF3 damage condition observed in the field. The results by the HBF, AIJ, and NCEER methods are suggested to further review the suitability of the existing MSFs.

\section{Authors' contributions}

CCL carried out the soil liquefaction evaluation accompanying with the discussion of parameter and model uncertainties and drafted the manuscript. $\mathrm{JHH}$ organized the framework of the study and carried out the description of the liquefied sites after site investigation. SYH carried out the evaluation of site response. All authors read and approved the final manuscript.

\section{Author details}

${ }^{1}$ National Center for Research on Earthquake Engineering, No. 200, Sec. 3, Xinhai Rd., Taipei 10668, Taiwan, ROC. ${ }^{2}$ Department of Civil Engineering, National Central University, No.300, Jhongda Rd., Jhongli City 32001, Taoyuan County, Taiwan, ROC.

\section{Acknowledgements}

The authors want to deeply express their sincere thanks to those people and organizations that help the survey team of NCREE to finish the reconnaissance and investigation works after earthquake. Without their helps, this paper cannot be completed.

\section{Competing interests}

The authors declare that they have no competing interests.

\section{Publisher's Note}

Springer Nature remains neutral with regard to jurisdictional claims in published maps and institutional affiliations.

Received: 20 February 2017 Accepted: 31 July 2017

Published online: 15 August 2017

\section{References}

AlJ (Architectural Institute of Japan) (2009) Design recommendation for architectural structure. (in Japanese)

Andrus RD, Stokoe KH II (1997) Liquefaction resistance based on shear wave velocity. In: Proceedings of NCEER workshop on evaluation of liquefaction resistance of soils, National Center for Research on Earthquake Engineering, State University of New York at Buffalo, pp 89-128

Bray JD, Stewart JP (2000) Chapter 8: damage patterns and foundation performance in Adapazari. Kocaeli, Turkey Earthquake of August 17, 1999 Reconnaissance Report. In: Youd TL, Bardet JP, Bray JD (eds) Earthquake Spectra, Supplement A to 16, pp 163-189

Construction and Planning Agency, MOI (2010) Seismic design specifications and commentary of buildings. (in Chinese)

Hwang JH, Yung CW (2003) Appraisal of SPT-N methods in liquefaction analysis by using the Chi-Chi earthquake data cases. Sino-geotechnics 98:79-90. (in Chinese)

Hwang JH, Chen CH, Juang CH (2012) Calibrating the model uncertainty of the HBF simplified method for assessing liquefaction potential of soils. Sino-geotechnics 133:77-86 (in Chinese)

Hwang JH, Yung CW, Chen CH (2005) Simplified methods for assessing liquefaction potential of soil by using hyperbolic cyclic resistance curves. Sino-geotechnics 103:53-64. (in Chinese)

Idriss IM (1990) Response of soft soil sites during earthquakes. In: Duncan JM (ed) Proceedings of H. Bolton seed memorial symposium, vol 2, pp $273-290$

Idriss IM (1997) Personal communication to T. L. Youd

Idriss IM, Sun JI (1992) User's Manual for SHAKE91. Center for Geotechnical Modeling, Department of Civil Engineering, University of California, Davis

Itasca Consulting Group, Inc. (2011) FLAC_fast Lagrangian analysis of continua, Ver. 7.0, User's Manual, Minneapolis, Itasca

Iwasaki T, Tatsuoka F, Tokida K, Yasuda S (1978) A practical method for assessing soil liquefaction potential based on case studies at various sites in Japan. In: Proceedings of the 2 nd international conference on microzonation for safer construction - research and application, San Francisco, CA, pp 885-896

Iwasaki T, Arakawa T, Tokida K (1982) Simplified procedures for assessing soil liquefaction during earthquakes. In: Proceedings of the conference on soil dynamics and earthquake engineering, Southampton, pp 925-939

Iwasaki T, Arakawa T, Tokida K (1984) Simplified procedures for assessing soil liquefaction during earthquakes. Int I Soil Dyn Earthq Eng Southampt 3:49-58

Jean WY, Chang YW, Wen KL, Loh CH (2006) Early estimation of seismic hazard for strong earthquakes in Taiwan. Nat Hazards 37(1-2):39-53

JRA (Japan Road Association) (1996) Road bridge specifications: part V Series of earthquake-proof design. (in Japanese)

Juang CH, Liu CN, Chen CH, Hwang JH, Lu CC (2008) Calibration of liquefaction potential index-a re-visit focusing on a new CPTU model. Eng Geol 102(1-2):19-30

NCREE (National Center for Research on Earthquake Engineering) (2016) 2016.02.06 Kaohsiung Meinong earthquake information, http://www. ncree.org/Ncree.aspx?id=17. (in Chinese)

Rayhani MHT, Naggar MHE, Tabatabaei SH (2008) Nonlinear analysis of local site effects on seismic ground response in the Bam earthquake. Geotech Geol Eng 26(1):91-100

Seed HB, Idriss IM (1971) Simplified procedure for evaluating soil liquefaction potential. J Soil Mech Found Div 97:1249-1273

Seed HB, Idriss IM (1982) Ground motions and soil liquefaction during earthquakes. Earthquake Engineering Research Institute Monograph, Oakland, CA

Seed HB, Tokimatsu K, Harder LF, Chung RM (1985) The influence of SPT procedures in soil liquefaction resistance evaluation. J Geotech Eng ASCE 111(12):1425-1445

Youd TL, Idriss IM (1997) Proceedings of the NCEER workshop on evaluation of liquefaction resistance of soils, Technical Report NCEER-97-0022 